\title{
Breath hydrogen after ingestion of the bulk sweeteners sorbitol, isomalt and sucrose in chocolate
}

\author{
BY ADAM LEE, ALBERT ZUMBE AND DAVID STOREY* \\ Department of Biological Sciences, University of Salford, The Crescent, Salford M5 4WT
}

(Received 4 March 1993 - Revised 9 August 1993-Accepted 17 August 1993)

\begin{abstract}
The effect of eating chocolate containing sugar alcohols as sweetening agents on colonic fermentation has been investigated by monitoring breath $\mathrm{H}_{2}$ levels. Levels were compared with those occurring after the consumption of normal, sugar-containing chocolate. Ten healthy volunteers aged 19 to 21 years ingested equal amounts of either sorbitol, isomalt or sucrose incorporated into standard chocolate bars. Breath $\mathrm{H}_{2}$ levels after consumption of chocolate containing either sorbitol or isomalt were significantly higher than those after consumption of chocolate containing sucrose $(P<0.001)$. After consumption of chocolate containing sorbitol, double the mean estimated volume of breath $\mathrm{H}_{2}$ was produced over $6 \mathrm{~h}$ compared with that produced after eating chocolate containing isomalt. Taken together with results relating to the incidence of intolerance symptoms, these findings demonstrate that sorbitol is associated with greater colonic fermentation compared with isomalt.
\end{abstract}

Breath hydrogen: Chocolate: Colonic fermentation: Sucrose: Isomalt: Sorbitol

$\mathrm{H}_{2}$ breath testing provides semi-quantitative information on the extent and duration of fermentation of unabsorbed dietary components (Bond \& Levitt, 1972) and the aim of the present study was to investigate the post-prandial breath $\mathrm{H}_{2}$ response of subjects following the ingestion of chocolate containing either isomalt, sorbitol or sucrose.

Sucrose, the most commonly used bulk sweetener, is an energy-rich substance having an energy value of $16.5 \mathrm{~kJ} / \mathrm{g}$ (Paul \& Southgate, 1978) and its consumption is associated with dental caries and elevated levels of plasma glucose and insulin (Swan et al. 1966; Russell, 1974). The sugar alcohols isomalt and sorbitol are both non-cariogenic and insulinindependent, with similar technological properties to those of sucrose (Kalbermatten et al. 1980; Grenby, 1983; Thiebaud et al. 1984; Grenby et al. 1989), Isomalt has an energy value of $8.4 \mathrm{~kJ} / \mathrm{g}$ (Spengler et al. 1987) and sorbitol contains $10 \mathrm{~kJ} / \mathrm{g}$ (Nutrition Council of the Netherlands, 1987), and both are thus potentially attractive to health-conscious individuals.

Isomalt and sorbitol are potentially advantageous bulk sweeteners and can be incorporated into confectionery products to replace sucrose. Chocolate is a useful vehicle in which to test bulk sweeteners because of its ease of consumption in comparison with hard sweets and toffees. It is much easier, for example, for subjects to consume $70 \mathrm{~g}$ chocolate in $10 \mathrm{~min}$ rather than $35 \mathrm{~g}$ toffees. Moreover, sucking toffees may introduce air into the stomach, risking complication of assessment of gastrointestinal side effects. Also, many formulations of chocolate containing relatively high doses of polyol are available in the European market and are potentially appealing to consumers because of their reduced caloric value and low cariogenicity.

Much attention has been paid to sorbitol, a derivative of the monosaccharide glucose, as a sweetener used in sugar-free products, but its ingestion at doses as low as $5 \mathrm{~g} / 24 \mathrm{~h}$ is associated with a positive breath $\mathrm{H}_{2}$ response (Hyams, 1983) and, at doses higher than $10 \mathrm{~g}$,

\footnotetext{
* For reprints.
} 
with gastrointestinal distress and diarrhoea. Colonic bacteria can ferment undigested carbohydrate and dietary fibre leading to the production of $\mathrm{H}_{2}, \mathrm{CH}_{4}$ and short-chain fatty acids; diarrhoea may occur if the fermentative capacity of the colon is exceeded (Tadesse \& Eastwood, 1978; Saunders \& Wiggins, 1981; McNeil, 1984). The production of excess intestinal gas and the occurrence of diarrhoea do not, for obvious reasons, appeal to potential consumers of sugar-free products.

Isomalt (Palatinit $\left.{ }^{(}\right)$, Palatinit Sussungsmittel $\mathrm{GmbH}$, Mannheim, Germany) is an equimolar mixture of the disaccharide alcohols D-glucosyl- $\alpha(1 \rightarrow 1)$-D-mannitol and Dglucosyl- $\alpha(1 \rightarrow 6)$-D-glucitol. Unlike sorbitol, isomalt is reported to undergo limited hydrolysis in the small intestine liberating glucose $(50 \%)$, sorbitol $(25 \%)$ and mannitol ( $25 \%$; Grupp \& Siebert, 1978). Nevertheless, isomalt is still considered a poor substrate for intestinal disaccharidases (Nilsson \& Jagerstad, 1987). Thiebaud et al. (1984) indicate that little ingested isomalt is hydrolysed in the small intestine, with most acting as a substrate for microbial fermentation in the colon leading to positive breath $\mathrm{H}_{2}$ profiles closely correlated with the quantity of isomalt ingested. It has been claimed by Fritz et al. (1985) and Spengler et al. (1987) that flatulence was the only gastrointestinal effect of significance when healthy individuals consumed daily doses of $50 \mathrm{~g}$ isomalt.

\section{METHODS}

\section{Subjects}

Ten healthy volunteers, five male and five female, between 19 and 21 years old were recruited from the student population of the Department of Biological Sciences of the University of Salford, U.K. Body mass indices (mean (SD)) were: male $22.65(1.43)$ and female $19 \cdot 79(1.56)$.

Pre-screening of potential volunteers ensured that they had no history of gastrointestinal disease or diabetes, and that they had not received antibiotics or used laxatives for 1 month before the study. Subjects were chosen who did not regularly eat or drink products containing isomalt, sorbitol or any other sugar alcohols. All volunteers gave written consent and were remunerated for their participation in the study. Ethical approval was provided by the University of Salford Occupational Health and Hygiene Service.

\section{Test materials}

Test products were supplied by Jacob Suchard A.G. (Neuchatel, Switzerland), as bars of milk chocolate with identical appearance and packaging. One product contained sucrose, one isomalt and the other sorbitol; bulk sweetener amounted to $45 \mathrm{~g} / 100 \mathrm{~g}$ chocolate, i.e. $31.5 \mathrm{~g}$ for each $70 \mathrm{~g}$ block. As a control, a $20 \mathrm{ml}$ dose of lactulose syrup $(0.67 \mathrm{~g} / \mathrm{ml}$; Duphar Laboratories, Southampton, Hants) was given in $250 \mathrm{~g}$ chicken soup, i.e. a total dose of $13.4 \mathrm{~g}$ lactulose. The dose of lactulose was given here as a positive control to check that all subjects gave a satisfactory and positive breath $\mathrm{H}_{2}$ response. Chicken soup was used as the vehicle for lactulose ingestion because (a) lactulose syrup is liquid and (b) the soup would deliver the dose of lactulose intact to the colon. It was surmised that a dose greater than $20 \mathrm{ml}$ would provoke unnecessary gastrointestinal symptoms and have a cathartic effect upon subjects.

\section{Study design and breath hydrogen measurement}

In a double-blind study subjects were tested with each product and control in randomized order, with test periods separated by periods of 1 week. Each bar was assigned a four digit random number by which it could be identified once the trial had finished. 
Because of the potential effect of lactose, fructose, dietary fibre and polyols upon colonic fermentation, the following dietary restrictions were enforced to ensure that there were only basal levels of $\mathrm{H}_{2}$ production before commencement of the breath $\mathrm{H}_{2}$ test proper. Alcohol was restricted because of its potentially adverse effect upon the fasting subject. Subjects were instructed to adhere to the following restrictions during the $24 \mathrm{~h}$ before eating each chocolate bar: (1) no more than $300 \mathrm{ml}$ milk; (2) no more than $300 \mathrm{ml}$ fresh fruit juice; (3) no alcohol; (4) no high fibre foods; (5) no products containing isomalt, sorbitol or other sugar alcohol. Dietary intakes were recorded to check whether these conditions had been satisfied.

Subjects fasted overnight and ate no solid food after 18.00 hours and no fluids after 24.00 hours. Pre-test $\mathrm{H}_{2}$ breath measurements were also recorded to check for abnormally high breath $\mathrm{H}_{2}$ concentrations which would indicate possible non-compliance with trial restrictions.

Each test product and the control meal had to be consumed within a $10 \mathrm{~min}$ period. Endalveolar breath samples were collected immediately after consumption of the test material and at $30 \mathrm{~min}$ intervals for $6 \mathrm{~h}$ thereafter. Samples of end-alveolar breath were obtained by subjects exhaling end-expiratory air into $60 \mathrm{ml}$ plastic syringes, and the $\mathrm{H}_{2}$ concentrations were measured using an electrochemical cell (Gas Measurement Instruments, Renfrew, Strathclyde).

\section{Gastrointestinal symptoms}

Each subject was provided with a pre-printed sheet on which to record the incidence and severity of any intolerance symptoms occurring during tests and for the remainder of each test day (about $18 \mathrm{~h}$ ). Notifiable symptoms were wind, colic (lower abdominal discomfort), bloating and belching, and stomach ache, and were classified as no incidence (normal), mild, moderate or severe. Stool frequency was recorded as the number of toilet visits and a consistency value assigned to the stools passed by the subject at each toilet visit, where 1 indicated the passage of loose stools; 2 indicated the passage of normal stools and 3 indicated the passage of hard stools. Mild diarrhoea was defined as the passage of loose stools on one occasion, moderate diarrhoea as the passage of loose stools on two occasions and severe diarrhoea as the passage of loose stools on three or more occasions during the test period. Because subjects were unmonitored during toilet visits, information relating to stool volume and the exact number of stools passed was not determined.

\section{Statistics}

The half-hourly breath $\mathrm{H}_{2}$ concentrations were compared using one-way analysis of variance and significant differences between mean values were determined using Student's paired $t$ tests. These data were considered to be parametric. Intolerance data were considered non-parametric and an exact test (Gart, 1969) was used to discern differences between products, taking into account those subjects experiencing the same symptoms while consuming different sugar alcohols.

\section{RESULTS}

Measurements of basal breath $\mathrm{H}_{2}$ excretion after overnight fasting revealed that levels were always within normal limits for all subjects, confirming total compliance with dietary restrictions.

The half-hourly breath $\mathrm{H}_{2}$ concentrations (mean and SEM) for the $6 \mathrm{~h}$ period after consumption of test materials and the control are shown in Fig. 1.

After consumption of test material there was a sharp increase in breath $\mathrm{H}_{2}$ concentration ( $>5 \mathrm{ppm}$ ) at the following times: sorbitol 87 (SE 26) min; isomalt 96 (SE 36) min. Peak 


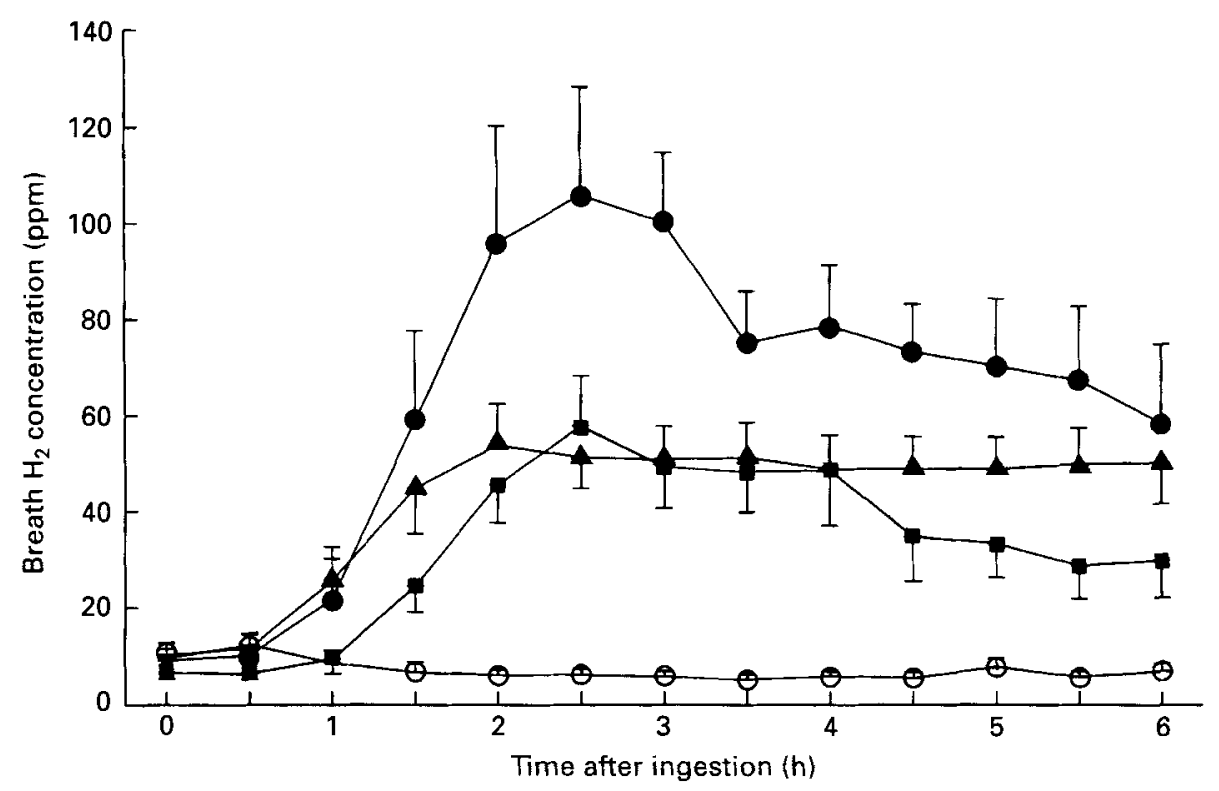

Fig. 1. Breath $\mathrm{H}_{2}$ concentration (ppm) after ingestion of $70 \mathrm{~g}$ chocolate containing $31.5 \mathrm{~g}$ of either sorbitol (C), isomalt $(\boldsymbol{E})$, or sucrose $(\mathrm{O})$ or a control meal containing $13.4 \mathrm{~g}$ lactulose $(\boldsymbol{A})$. Values are means for ten subjects with their standard errors represented by vertical bars.

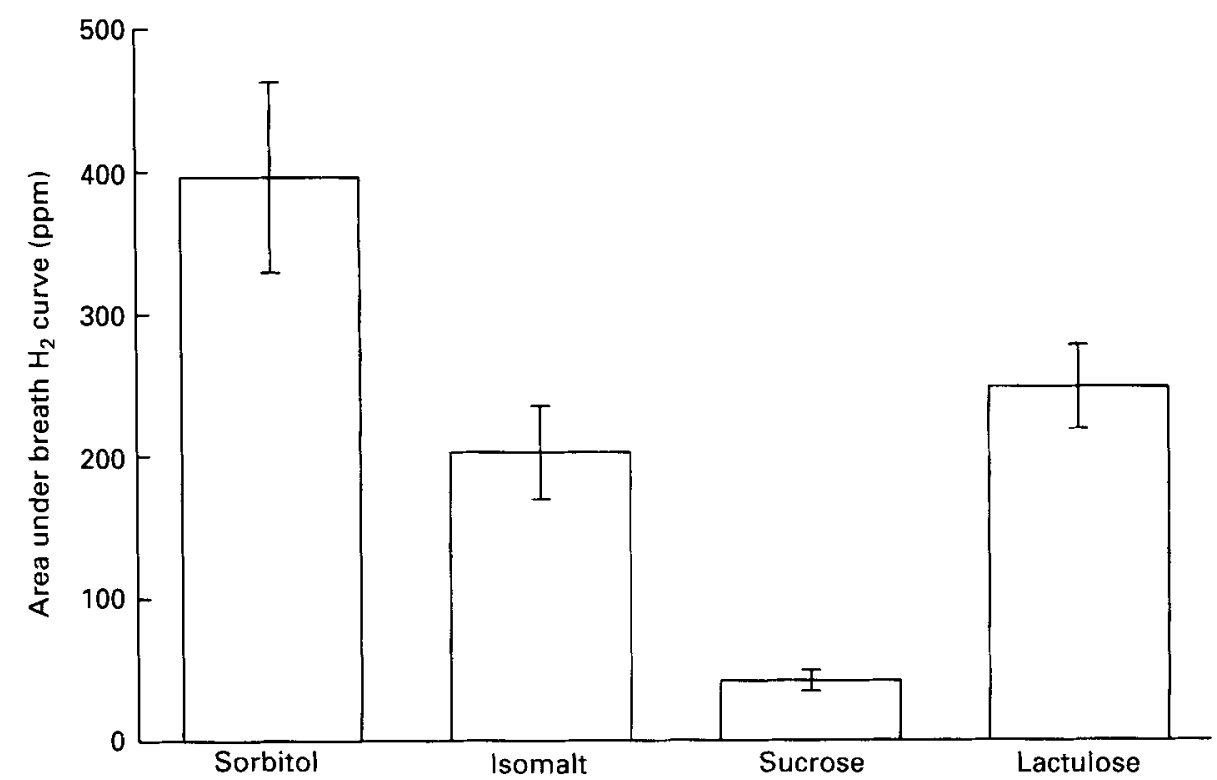

Fig. 2. Area under breath $\mathrm{H}_{2}$ curve (cumulative breath $\mathrm{H}_{2}$ excretion, ppm) after ingestion of $70 \mathrm{~g}$ chocolate containing $31.5 \mathrm{~g}$ of either sorbitol, isomalt, or sucrose or a control meal containing $13.4 \mathrm{~g}$ lactulose. Values are means for ten subjects with their standard errors represented by vertical bars.

breath $\mathrm{H}_{2}$ levels occurred as follows: sorbitol 183 (SE 72) min; isomalt 168 (SE 45) min. Breath $\mathrm{H}_{2}$ concentrations did not increase following consumption of the product containing sucrose.

The cumulative $\mathrm{H}_{2}$ excretion was estimated by summation of the half-hourly breath $\mathrm{H}_{2}$ 
Table 1. Intolerance symptoms after ingestion of $70 \mathrm{~g}$ chocolate containing $31.5 \mathrm{~g}$ of either sorbitol, isomalt or sucrose or a control meal containing $13.4 \mathrm{~g}$ lactulose

(Number of subjects from groups of ten reporting symptoms)

\begin{tabular}{|c|c|c|c|c|}
\hline & Sorbitol & Isomait & Sucrose & Lactulose \\
\hline \multicolumn{5}{|l|}{ Diarrhoea } \\
\hline Mild & 4 & 0 & 0 & 1 \\
\hline Moderate & 0 & 0 & 0 & 0 \\
\hline Severe & 1 & 0 & 0 & 1 \\
\hline \multicolumn{5}{|l|}{ Flatulence } \\
\hline Mild & 3 & 4 & 1 & 4 \\
\hline Moderate & 2 & 1 & 0 & 1 \\
\hline Severe & 0 & 0 & 0 & 0 \\
\hline \multicolumn{5}{|l|}{ Colic } \\
\hline Mild & 2 & 4 & 1 & 2 \\
\hline Moderate & 0 & 1 & 0 & 0 \\
\hline Severe & 1 & 0 & 0 & 0 \\
\hline \multicolumn{5}{|c|}{ Stomach ache } \\
\hline Mild & 0 & 5 & 1 & 2 \\
\hline Moderate & 5 & 0 & 0 & 0 \\
\hline Severe & 0 & 0 & 0 & 0 \\
\hline \multicolumn{5}{|c|}{ Bloating and belching } \\
\hline Mild & 4 & 4 & 1 & 1 \\
\hline Moderate & 0 & 0 & 0 & 0 \\
\hline Severe & 0 & 0 & 0 & 0 \\
\hline
\end{tabular}

Mod, moderate symptoms; Sev, severe symptoms.

values from 1 to $6 \mathrm{~h}$ for each subject. Mean cumulative and estimated areas under the breath $\mathrm{H}_{2}$ curves can be attributed to fermentation of unabsorbed carbohydrate and are shown in Fig. 2.

Mean estimated breath $\mathrm{H}_{2}$ excretion was significantly lower after consumption of the product containing sucrose $(P<0.001)$ than after consumption of the products containing the sugar alcohols sorbitol, isomalt or lactulose. Breath $\mathrm{H}_{2}$ excretion following consumption of $70 \mathrm{~g}$ chocolate containing $31.5 \mathrm{~g}$ sorbitol was significantly higher $(P<0.01)$ than after consumption of $70 \mathrm{~g}$ chocolate containing $31.5 \mathrm{~g}$ isomalt.

Lactulose is used routinely in hospital clinics to assess intestinal fermentation and a standard dose of lactulose was given as a test meal to all subjects. Despite its low dose $(13.4 \mathrm{~g})$ compared with the chocolate test materials $(31.5 \mathrm{~g})$, on a gram-for-gram basis it elicited the highest cumulative breath $\mathrm{H}_{2}$ excretion. Figures are: sorbitol, 12.6 (SE 6.7) $\mathrm{ppm} / 6 \mathrm{~h}$ per g product; isomalt, 6.4 (SE 3.3 ) $\mathrm{ppm} / 6 \mathrm{~h}$ per g product ; lactulose, 18.5 (SE 7.0) $\mathrm{ppm} / 6 \mathrm{~h}$ per g product.

The number of subjects reporting various symptoms of gastrointestinal intolerance during the test period and for the remainder of the day is shown in Table 1. Ten subjects made a total of twelve toilet visits following consumption of the isomalt product and ten subjects made a total of fourteen toilet visits following consumption of the sorbitol product. No subject made more than two visits following ingestion of the isomalt product and only one subject made three toilet visits following ingestion of the sorbitol product.

The incidence of diarrhoea (classified as the passage of loose stools on one, two or three occasions) after ingestion of the sorbitol product was significantly higher $(P<0.05)$ than after ingestion of the isomalt or sucrose products. The number of subjects reporting wind, 
colic, bloating and belching or stomach ache was not significantly different after ingestion of products containing either sorbitol, isomalt, sucrose or lactulose.

\section{DISCUSSION}

The consumption of sugar-free products has positive health benefits because of their nonassociation with dental caries (Grenby et al. 1989) and their reduced energy value (Thiebaud et al. 1984). However, their use as sugar substitutes in confectionery may be limited because of the effects of increased colonic fermentation as quantified by the $\mathrm{H}_{2}$ breath test.

Varying amounts of carbohydrates remain unabsorbed by the small intestine and, together with dietary fibre and partially nutritive sugar substitutes such as isomalt, they form a carbohydrate pool available for bacterial fermentation in the colon (Tadesse \& Eastwood, 1978; Stephen et al. 1983; Stone-Dorshaw \& Levitt, 1987). The gases of colonic fermentation $\left(\mathrm{H}_{2}, \mathrm{CH}_{4}\right.$ and $\left.\mathrm{CO}_{2}\right)$ may be partially reabsorbed across the colonic mucosa and detected in breath samples, though some remain unabsorbed and are passed as flatus. Other products of fermentation are the short-chain fatty acids notably acetate, propionate and butyrate which, upon absorption across the colonic mucosa, may be metabolized to yield energy. Secondary metabolism of short-chain fatty acids by colonic bacteria may produce gas. If the fermentative capacity of the colon is exceeded, osmotic diarrhoea occurs (Tadesse \& Eastwood, 1978; Saunders \& Wiggins, 1981; McNeil, 1984).

This study has demonstrated that both isomalt and sorbitol, as well as the totally unabsorbable disaccharide-alcohol lactulose, result in an elevated breath $\mathbf{H}_{2}$ profile compared with that observed after sucrose $(P<0.001)$. Similar results were observed by D. M. Paige (unpublished results) who also reported an inverse relationship between blood glucose and breath $\mathrm{H}_{2}$ after ingestion of $35 \mathrm{~g}$ isomalt or sucrose.

The breath $\mathrm{H}_{2}$ responses for sucrose can be considered to be basal breath $\mathrm{H}_{2}$ values because sucrose is normally completely hydrolysed and absorbed in the small intestine.

Sorbitol consumption led to the production of twice the mean estimated volume of $\mathrm{H}_{2}$ over $6 \mathrm{~h}$ compared with isomalt (Fig. 2), a difference which is significant at the $1 \%$ confidence limit.

Following consumption of test products the estimated mean time taken for detectable increase in breath $\mathrm{H}_{2}$ to occur (effectively the oro-caecal transit time) was 87 (SE 26) min for sorbitol and lactulose. For isomait this interval was 96 (SE 37) $\mathrm{min}$. The difference may be accounted for by a greater degree of non-absorption of both sorbitol and lactulose in the small intestine (Grupp \& Siebert, 1978; Hyams, 1983).

The priority of the present study was not to assess subjective intolerance but, nevertheless, it was deemed appropriate to record gastrointestinal symptoms following consumption of polyol-containing products. Five subjects experienced diarrhoea (classified as the passage of loose stools on one or more occasion) after ingesting sorbitol but none after ingesting either isomalt or sucrose $(P<0 \cdot 05)$. Sorbitol also induced a greater severity of intestinal gaseousness when compared with isomalt or sucrose. Observed frequencies were small and no statistical conclusions can be made, but the observations agree with those of Hyams (1983) that ingestion of doses of sorbitol as low as 10 to $20 \mathrm{~g}$ may produce intolerance symptoms, including diarrhoea, in healthy subjects.

Previous gastrointestinal tolerance studies of sugar alcohols have focused on the ingestion of the native material whereas this investigation has used sorbitol and isomalt incorporated into a palatable confectionery product. The ingestion of chocolate containing sorbitol led to a much elevated breath $\mathrm{H}_{2}$ response compared with that which occurred after the ingestion of chocolate containing an equal amount of isomalt. Taken together 
with data relating to the incidence of intolerance, these results suggest that isomalt has advantages over sorbitol as a bulk sweetener.

The authors gratefully acknowledge the help and advice given by $\mathrm{Mr}$ R. A. Brinkworth during the execution of this study and during preparation of the original manuscript. The expert assistance given by Dr P. A. Scarfe, University of Salford, in the statistical analysis of our data is also acknowledged with gratitude.

\section{REFERENCES}

Bond, J. H. \& Levitt, M. D. (1972). Use of pulmonary hydrogen $\left(\mathrm{H}_{2}\right)$ measurements to quantitate carbohydrate absorption. Journal of Clinical Investigation 51, 1219-1225.

Fritz, M., Siebert, G. \& Kaspar, H. (1985). Dose dependence of breath hydrogen and methane in healthy volunteers after ingestion of a commercial disaccharide mixture Palatinit. British Journal of Nutrition 54, 389-400.

Gart, J. J. (1969). An exact test for comparing matched proportions in crossover designs. Biometrika 56, 75-80.

Grenby, T. H. (1983). Nutritive sucrose substitutes and dental health. In: Developments in Sweeteners, pp. 51-82 [T. H. Grenby, K. J. Parker and M. G. Lindley, editors]. Barking, Essex: Applied Science Publishers.

Grenby, T. H., Philips, A. \& Mistry, M. (1989). Studies of the dental properties of lactitol compared with five other bulk sweeteners in vitro. Caries Research 23, 315-319.

Grupp, U. \& Siebert, G. (1978). Metabolism of hydrogenated palatinose, an equimolar mixture of $\alpha-D-$ glucopyranosido-1-6-sorbitol and $\alpha$-D-glucopyranosido-1-6-mannitol. Research in Experimental Medicine (Berlin) 173, 261-278.

Hyams, S. (1983). Sorbitol intolerance: An unappreciated cause of functional gastrointestinal complaints. Gastroenterology 84, 30-33.

Kalbermatten, N., Ravussin, E., Maeder, E., Geser, C., Jequier, E. \& Felber, J. P. (1980). Comparison of glucose, fructose, sorbitol and xylitol utilisation in humans during insulin suppression. Metabolism 1, 62-66.

McNeil, N. I. (1984). The contribution of the large intestine to energy supplies in man. American Journal of Clinical Nutrition 39, 338-342.

Nilsson, U. \& Jagerstad, M. (1987). Hydrolysis of lactitol, maltitol and Palatinit by human intestinal biopsies. British Journal of Nutrition 58, 199-206.

Nutrition Council of the Netherlands (1987). The Energy Value of Sugar Alcohols: Recommendation of the Committee on Polyalcohols. The Hague: Department of Health.

Paul, A. A. \& Southgate, D. A. T. (1978). McCance and Widdowson's The Composition of Foods, 4th ed. London: H.M. Stationery Office.

Russell, A. L. (1974). Carbohydrates as a causative factor in dental caries: Epidemiological evidence. In Sugars in Nutrition, pp. 635-643 [H. L. Sipple and K. W. McNutt, editors]. London: Academic Press.

Saunders, D. R. \& Wiggins, H. S. (1981). Conservation of mannitol, lactulose and raffinose by the human colon. American Journal of Physiology 241, G397-G402.

Spengler, M., Somogyi, J. C., Pletcher, E. \& Boehme, K. (1987). Tolerability, acceptance and energetic conversion in isomalt (Palatinit) ${ }^{\circledR}$ in comparison with sucrose. Aktuelle Ernahrungsmedizin 6 (12), 210-214.

Stephen, A. M., Haddad, A. C. \& Philips, S. F. (1983). Passage of carbohydrate into the colon: Direct measurements in humans. Gastroenterology 85, 589-595.

Stone-Dorshaw, T. \& Levitt, M. D. (1987). Gaseous response to ingestion of a poorly absorbed fructooligosaccharide sweetener. American Journal of Clinical Nutrition 46, 6I-65.

Swan, D. C., Davidson, P. \& Albrink, M. J. (1966). Effect of simple and complex carbohydrate on plasma nonesterified fatty acids, plasma sugar and plasma insulin during oral carbohydrate tolerance tests. Lancet $9,60-63$.

Tadesse, K. \& Eastwood, M. A. (1978). Metabolism of dietary fibre components in man assessed by breath hydrogen and methane. British Joumal of Nutrition 40, 393-395.

Thiebaud, D., Jacot, E., Schmitz, H., Spengler, M. \& Felber, J. P. (1984). Comparative study of isomalt and sucrose by means of indirect calorimetry. Metabolism 33, 808-813. 